\title{
PENGALAMAN SEKSUAL PADA PEREMPUAN DENGAN KANKER SERVIKS YANG SEDANG MENJALANI KEMOTERAPI
}

\section{SEXUAL EXPERIENCE IN WOMEN WITH CERVICAL CANCER THAT IS UNDERGOING CHEMOTHERAPY}

\author{
Mery Arianti ${ }^{1}$, Irna Nursanti², M. Natsir Nugroho ${ }^{3}$ \\ ${ }^{1}$ Mahasiswa Program Studi Magister FIK Universitas Muhammadiyah Jakarta \\ AKPER Bunda Delima Lampung \\ ${ }^{2,3}$ Program Studi Magister FIK Universitas Muhammadiyah Jakarta \\ Email: ariantimery@gmail.com
}

\begin{abstract}
sexual experience in women with cervical cancer that is undergoing chemotherapy. Cervical cancer is the fourth most common cancer in women with an estimated 570,000 new cases in 2018 or representing 6.6\%. At Dharmais Cancer Hospital for four consecutive years cervical cancer is the second most cervical cancer causes serious problems in a woman's life because it attacks the reproductive organs which is a very important part for women because it is closely related to meeting sexual needs. The purpose of this study is to explore the sexual experiences of women with cervical cancer who are undergoing chemotherapy. This research uses a qualitative approach with a descriptive phenomenological approach. Data were collected by semi-structured interviews and analyzed by editing analysis models. Five women with cervical cancer who were undergoing chemotherapy participated in this study. Samples were obtained by purposive sampling. In this study identified four themes found in women with cervical cancer who are undergoing chemotherapy, such as: sexual changes, sexual activity, expressions of affection and hope for health workers. Data validity is validated by assessing the credibility, dependability, confirmability and data transferability. From the results of this study several recommendations were given, that is : for nursing education to improve the competence of students in nursing care for the aspects of sexuality, for health services to increase awareness of sexuality issues and for further research both qualitatively and quantitatively aimed at couples about how sexual experiences with wives who have cervical cancer undergoing chemotherapy
\end{abstract}

Keywords: Cervical Cancer, Chemotherapy, Sexual Experience

\begin{abstract}
Abstrak Pengalaman Seksual Pada Perempuan Dengan Kanker Serviks Yang Sedang Menjalani Kemoterapi. Kanker serviks adalah kanker paling sering keempat pada wanita dengan perkiraan 570.000 kasus baru pada tahun 2018 atau mewakili 6,6\%. Di Rumah Sakit Kanker Dharmais selama empat tahun berturut-turut penyakit kanker serviks adalah terbanyak keduaKanker serviks menyebabkan masalah serius terhadap kehidupan seorang wanita karena menyerang organ reproduksi yang merupakan bagian sangat penting bagi wanita karena terkait erat dengan pemenuhan kebutuhanseksual.Tujuan penelitian ini adalah untuk mengeksplorasi pengalaman seksual perempuan dengan kanker serviks yang sedang menjalani kemoterapi.Penelitian ini menggunakan pendekatan kualitatif dengan pendekatan fenomenologi deskriptif. Data dikumpulkan dengan wawancara semi terstruktur dan dianalisis dengan model analisa editing. Sebanyak lima perempuan dengan kanker serviks yang sedang menjalani kemoterapi ikut berpartisipasi dalam penelitian ini. Sample diperoleh dengan purposive sampling. Dalam penelitian ini teridentifkasi empat tema yang ditemukan pada perempuan dengan kanker serviks yang sedang menjalani kemoterapi, yaitu: perubahan seksual, aktivitas seksual, ekspresi kasih sayang dan harapan terhadap petugas kesehatan. Keabsahan data divalidasi dengan menilai kredibilitas, dependabilitas, konfirmabilitas dan transferabilitas data. Dari hasil penelitian ini beberapa rekomendasi yang diberikan yaitu : bagi pendidikan keperawatan untuk meningkatkan kompetensi peserta didik pada asuhan keperawatan aspek seksualitas, bagi pelayanan kesehatan untuk meningkatkan kepedulian terhadap masalah seksualitas dan bagi penelitian selanjutnya baik kualitatif maupun kuantitatif ditujukan pada pasangan tentang bagaimana pengalaman seksual dengan istri yang mengalami kanker serviks sedang menjalani kemoterapi.
\end{abstract}

KataKunci: Kanker Serviks, Kemoterapi, Pengalaman Seksual 


\section{PENDAHULUAN}

Kanker adalah penyebab kematian nomor dua di dunia setelah penyakit kardiovaskuler. Lebih kurang terdapat 7.500 .000 orang meninggal akibat kanker, dan terdapat $>70 \%$ kematian terjadi di negara miskin atau berkembang (WHO \& World Bank, dalam Kemenkes, 2015). Secara umum terdapat 18,1 juta kasus baru dan 9,6 juta kematian pada tahun 2018 (IARC, WHO,2018).

Prevalensi kanker dalam 5 tahun terakhir di seluruh dunia, kira -kira 43.800.000 (IARC/WHO, 2018). Prevalensi kanker di Indonesia sendiri adalah $1,8 /$ mil penduduk dan prevalensi tertinggi menurut provinsi di Indonesia ditempati oleh DIY yaitu 4,9 / mil sedangkan prevalensi kanker untuk Lampung adalah 1,7 / mil (Riskesdas 2018).

Kanker pada organ reproduksi perempuan mempengaruhi fungsi seksual bagi $\pm 50 \%$ dari perempuan - perempuan termasuk kepuasan seksual (Afiyanti \& Pratiwi, 2016).

Seks merupakan salah satu komponen kebutuhan dasar manusia.Seksualitas merupakan salah satu faktor yang berperan dalam menentukan kebahagiaan perkawinan.Seksualitas didefinisikan secara luas sebagai keinginan menjalin hubungan, kehangatan, kemesraan, atau cinta (Stuart,2002).

Seksualitas manusia merupakan fenomena kompleks. Seksualitas dapat diekspresikan tidak hanya melalui hubungan aktivitas seksual semata (sexual intercourse), namun dapat diekspresikan juga dengan cara lain (non sexual intercourse) seperti melakukan kontak fisik (berpelukan, berciuman, memberi sentuhan),memberikan kasih sayang, cinta kasih, sikap empati, member peduli.

Hasil penelitian oleh Afiyanti dan Milanti, tahun 2013 dengan menggunakan metode kuantitatif pada 53 penderita kanker serviks mendapatkan bentuk keluhan berupa kekhawatiran pada organ seksual seperti : terjadinya perdarahan setelah berhubungan, nyeri saat berhubungan karena vagina terasa sempit dan tidak dilumasi. Dampak penurunan hasrat seksual pada pasangan, seperti :mencari alasan untuk menolak hubungan seksual, prasangkaterhadap pasangan, merasa terpaksa untuk terpenuhinyahasrat seksual suami, menerima kemarahan pasangan, kesediaan untuk membiarkan pasangan menikah dengan wanitalain.

Hasil penelitian oleh Kulle at al dalam bentuk crosssectional study pada 54 penderita kanker serviks didapatkan keluhan seksual antara lain :penurunan fungsi seksual, kehilangan libido, vagina menjadi kering, nyeri saat berhubungan, sedangkan pada pasangan mengalami emosi negatif, merasa ada jarak, merasa kesepian.

Modalitas terapi kanker dapat memperpanjang periode bebas kanker dan ketahanan hidup pasien, tetapi efek pengobatan kanker serviks menyebabkan gangguan dan disfungsi seksual yang mempengaruhi kualitas hidup sebagai wanita. Berbagai fenomenadan keluhan seksual pada wanita kanker serviks menimbulkan pertanyaan bagaimana pengalaman seksual pada perempuan dengan kanker serviks yang sedang menjalani kemoterapi sehingga melakukan penelitian yang bertujuan untuk mengeksplorasi pengalaman seksual perempuan dengan kanker serviks yang sedang menjalani kemoterapi

\section{METODE}

Penelitian ini dilakukan dengan menggunakan metode kualitatif pendekatan fenomenologi .Instrumen penelitian adalah peneliti dibantu alat pengumpulan data, yaitu lembarobservasi, pedoman wawancara, catatan lapangan, gambar/foto, dan alat perekam digital.Prosedur pengambilan data adalah dengan wawancara mendalam, $F G D /$ DKT, dan observasi.Penelitian dilakukan setelah lolos kaji etik dan mendapat izin dari tempat penelitian yaitu RSUD dr.H.Abdul Moeloek Provinsi Lampung. Waktu penelitian adalah April - Mei 2019. Pengambilan data dimulai setelah mendapat persetujuan responden.

Pengambilan sampel menggunakan tehnik purposive sampel dengan penentuan responden dianggap memadai apabila telah ke taraf “redundancy".Sebanyak 5 responden berpartisipasi dalam penelitian ini. Analisa data dilakukan dengan Model Analisa Editing di mana peneliti berperan sebagai interpreter dan divalidasi dengan tehnik kredibilitas, dependabilitas, konfirmabilitas, dan transferabilitas

\section{HASIL}

Hasil penelitian mengidentifikasi 4 tema yang menjelaskan permasalahan penelitian, yaitu :Perubahan pada perempuan dengan kanker serviks yang sedang menjalani kemoterapi, aktivitas perempuan dengan kanker 
serviks yang sedang menjalani kemoterapi, ekspresi kasih sayang suami pada perempuan dengan kanker serviks yang sedang menjalani kemoterapi, dan harapan perempuan dengan kanker serviks yang sedang menjalani kemoterapi terhadap petugas kesehatan.

Beberapa kutipan pernyataan partisipan yang menunjukkan terjadinya perubahan seksual, adalah sebagai berikut:

“... sesudah sakit ini terus dikemoterapi saya sudah nggak ada lagi hasrat untuk berhubungan dengan suami...malah kalo suami suka deket-deketin rasanya gimana gitu, pokoknya gak sukalah di deketin sama suami..." (Pl)

“ Sejak di kemo, saya sudah nggak ada keinginan untuk berhubungan lagi dengan suami...sayasudahnggakadasamasekali hasratkadangkalausuamiinginmengajak berhubungan, dalam hati saya ya Allah, sudahlah suami saya tidak usah deket- deket lagi atau mencumbu saya... "(P2)

"Kadang kalau suami saya ingin mengajak berhubungan, dalam hati saya ya Allah kenapa sih, sudahlah tidak usah dekat-dekat, tidak usah bercumbu...suami saya bilang " saya ingin berhubungan, tapi belum apa-apa, baru mendekat kamu sudah marah-marah “ (P3)

Kutipan pernyataan partisipan untuk perubahan aktivitas seksual adalahsebagai berikut:

"Ya terpaksa namanya kewajiban, tetapi karena kondisi penyakit saya ini suami juga memahami...saya sama suami nggak lagi berhubungan kayak dulu...selama ini saya sudah merasakan kenikmatan itujadi kalau sekarang tidak lagi saya ya ikhlas... "(P1)

“...sekarang sudah jarang berhubungan palingcepat2minggusekali,kalosebelum sakit seminggu sekali...suami saya juga sudah jarang minta untuk berhubungan " $(P 2)$

“...kita berhubungan badannya sudah berkurang paling 2 minggu sekali...” (P5)

Ekspresi seksual tidak hanya melalui hubungan seksual (sexual intercourse), tetapi dapat juga diekspresikan dengan cara lain (nonsexual intercourse) seperti : pelukan, ciuman, sentuhan, perhatian, kasih sayang, empati, kepedulian, dan kedekatan emosional (Pratiwi, 2016).

Kutipan pernyataan partisipan sebagai berikut:

“...suami saya semakin lebih perhatian...beberapa hari setelah kemoterapi, saya suka lemas, mual, tidak nafsu makan, suami kadang suka pijat saya...saya merasa suami semakin lebih perhatian suami menasehati supayaselalu sabar dan berdoa untukkesembuhan"(Pl)

“...ya dia suka ke arahsentuhan-sentuhan begitu...memeluk... mencium... tapi saya yang tidak suka..." (P3)

Perawat memiliki multi peran baiksebagai pelaksana pelayanan, pendidik,konselor,

advocate, manager, peneliti, serta sebagai change agent (Perry \& Potter, 2001). Penelitian ini menunjukkan bahwa perempuan mengharapkan informasi melalui penyuluhan bagi dirinya maupun pasangan.

Kutipan pernyataan partisipan sebagai berikut:

“...saya berharap mereka tetap baik kepada saya dan yang lainnya, saya berterima kasih dengan bantuan yang sudah diberikan...tapi untuk masalah suami istri kayaknya malu kalo mau nanya..." (P1)

“... kalau harapan saya mereka harus lebih detil lagi menjelaskan sama pasien tentang bahaya-bahaya kemoterapi pada keluarga, sekarang kan anak yang lagi hamildirumah,dokterhanyabilangkalau selama empat hari setelah kemo jangan berhubungan dulu, piring, gelas dicuci sebelum dipakai anak-suami, kalau buang airkecildiklosetdandisiramyangbanyak (P3) 


\section{PEMBAHASAN}

Perempuan dengan kanker serviks mengalami kerentanan dengan berbagai keluhan fisik dan psikologis karena menya dari bahwa kondisinya berdampak serius dalam kehidupannya, seperti kematian serta hilangnya kemampuan menjalankan hubungan seksual (Alligood, 2014).Faktor yang sangat mempengaruhi adalah stadium, jenis terapi yang diberikan, umur, dan status kesehatan perempuan secara keseluruhan (Otto, 2001)

Gangguan seksualitas pada penderita kanker serviks akibat efek terapi kanker serviks dapat menyebabkan disfungsi seksual yang memengaruhi kualitas hidup perempuan.Banyak studi melaporkan bahwa para survival kankerserviks mengalami berbagai permasalahan seksualitas yang memberikan dampak buruk pada kualitas hidup. Perubahan keluhan seksual fisik dan psikologis (Klee dan Machin, 2000; Wenzel, et al.,2005; Burns, 2007, dalam Afiyanti 2018).

Ekspresi seksual tidak hanya melalui hubungan seksual (sexual intercourse), tetapi dapat juga diekspresikan dengan cara lain (nonsexual intercourse) seperti : pelukan, ciuman, sentuhan, perhatian, kasih sayang, empati, kepedulian, dan kedekatan emosional (Pratiwi, 2016).

Perawat maternitas sebagai bagian dari pelayananprofessional juga berperan penting dalam memberikan penyuluhan termasukkonseling.

Kurangnya perhatian petugas pada masalah seksual pada pasien kanker serviks yang sedang menjalani terapi juga didukung oleh penelitian sebelumnya (Afiyanti, dkk, 2014)

Hasil penelitian juga menunjukkan harapan dari perempuan bahwa petugas lebih proaktif untuk memberikan informasi terkait seksualitas karena masalah seksual masih menjadi sesuatu yang tabu untukdibicarakan.

Berdasarkan hasil penelitian didapatkan empat tema yaitu Perubahan seksual, aktivitas seksual, ekspresi kasih sayang suami, dan harapan terhadap petugaskesehatanpadaperempuandengan kanker serviks yang sedang menjalani kemoterapi.

\section{SIMPULAN}

Pengalaman seksual pada pasien kanker serviks yang sedang menjalani kemoterapi adalah adanya beberapa perubahan seksual yang terkait dengan keluhan-keluhan fisik psikologis yang mempengaruhi hubungan seksual, aktivitas seksual yang terkait dengan frekwensi dan cara melakukan hubungan seksual yang mengalami perubahan, ekspresi kasih sayang yang terkait dengan bentuk ungkapan pemenuhan kebutuhan seksual noncoital intercourse

Harapan terhadap petugas kesehatan yang mendapat respon baik tetapi masih diharapkan untuk lebih proaktif dalam mengkomunikasikan hal-hal yang berhubungan dengan pengobatan yang berhubungan dengan anjuran dan larangan. Pada dasarnya semua partisipan menyetujui untuk mendapatkan penyuluhan seksualitas pada perempuan dengan kanker serviks yang 
sedang menjalani pengobatan kemoterapi

\section{SARAN}

1. Bagi Pendidikan Keperawatan

Aspek seksualitas pada dasarnya sudah menjadi bagian dari ilmu keperawatan yang tertuang dalam materi kurikulum pendidikan keperawatan. Dari hasil penelitian ini diharapkan agar kompetensi peserta didik yang berhubungan dengan asuhan keperawatan pada aspek seksualitas lebih dikembangkan lagi, terutama dalam membentuk persepsi dan sikap personal sebagai bagian penting untuk dimiliki seorang perawat agar dapat merasa nyaman sekaligus memberi kenyamanan pada pasien dalam mengkomunikasikan seksualitas.

2. Bagi Pelayanan Kesehatan

Seksualitas masih menjadi hal yang tabu bagi sebagian perempuan di Indonesia untuk dibicarakan terbuka apalagi secara individual, sehingga perlu untuk meningkatkan kemampuan petugas dalam kepedulian terhadap masalah seksualitas pada pasien dengan kanker serviks. Kepedulian akan dapat meningkatkan rasa percaya pasien kepada petugas. Bentuk kepedulian menjadi salah satu tugas institusi pelayanan kesehatan, dengan memasukkan materi kedalam program pendidikan kesehatan dan konseling. Kepedulian ini akan meningkatkan kepercayaan diri pasien, yang ke depannya berdampak bagi peningkatan kesehatan pasien.

3. Bagi Penelitian Selanjutnya

Hasil penelitian ini dapat dijadikan rujukan penelitian selanjutnya baik penelitian kualitatif maupun kuantitatif, dan penelitian yang ditujukan pada pasangan tentang bagaimana pengalaman seksual dengan istri yang mengalami kanker serviks dan menjalani pengobatan kemoterapi.

\section{DAFTAR PUSTAKA}

American Cancer Society (ACS). 2014.

Global Cancer Facts \& Figures $2^{\text {nd }}$ Edition.Availablefrom:http://www.br eastcancer.org/symptoms/understand bc/stat istics, di unduh pada 10 Desember 2018

Aminati D. 2013. Cara Bijak Menghadapi dan Mencegah Kanker Leher Rahim (Serviks).Yogyakarta: BrillianBooks.

Alligood, M. R. (2014). Nursing theory \& their work (8 th ed). The CV Mosby Company St. Louis. Toronto. Missouri: Mosby Elsevier. Inc

Afiyanti,YatidanRachmawati,I.N,(2014)

Metodologi penelitian kualitatifdalam riset keperawatan, Jakarta, RajaGrafindoPersada.

Afiyanti, Yati dan Milanti ,Ariesta, 2012, Physical sexual and intimate relationhip concerns among Indonesian cervical cancer survivors: $A$ phenomenological study, Wiley Publishing Asia Pty Ltd., Nursing and HealthSciences(2013), 15,151-156,

di unduh pada 10 Januari 2019 Afiyanti, Yati., dkk, (2014), Women and

Experiences of Sexual Problem after Cervical Canccer Treatment : Lesson from Indonesian Women, Makara J. Health Res., (2014), 18 (2) : .51-57

doi:10.7454/msk.v $18 \mathrm{i} 2.3605$ di unduh pada 10 Januari 2019

Dwipoyono, B. (2009). Kebijakan pengendalian penyakit kanker serviks di Indonesia.

Everett, Suzanne. (2007). Buku Saku Kontrasepsi dan Kesehatan Seksual Reproduksi. Jakarta :EGC.

Fitriana, N. A., \& Ambarini, T. K. (2012).

Kualitas pada kanker serviks yang menjalani pengobatan radioterapi. 
Jurnal Psikologi Klinis danKesehatan Mental, 1 (02).di

unduh pada 12 Januari 2019

Hunter, J.L., (2014), The Impact of Cervical Cancer Treatment on SexualFunction and Intimate Relationships:Is Anyone Listening?,OpenJournalofObstetrics and Gynecology, 2014, 4, 479-490 Published Online June 2014 in dx.doi.org/10.4236/ojog.2014.48069, di unduh pada 12 Januari2019

International Agency for Research on Cancer (IARC), Estimated cancer incidence, mortality, and prevalence world wide in (2014). GLOBOCAN, WHO 2014

Kemenkes RI. Laporan Hasil Riset Kesehatan Dasar (Riskesdas) Indonesia tahun (2018).Jakarta :

Kemenkes RI, (2018), Data dan Informasi Profil Kesehatan Indonesia 2017, Jakarta: BadanPenelitiandan Pengembangan Kesehatan Kemenkes RI;2018.

Kuile, M.M, ter, at al, (2016), Cervical cancer survivors and partners' experience with sexual dysfunction and psychosexual support, support care cancer, 24;16791687 DOI 10.1007/s 00520-0520-0152928 
